Altenburger, P. 150

Arranz, A. 134

Arranz, L. 157

Baum, S. 150

Bay, M.L. 193

Berbert, L.R. 213

Besedovsky, H.O. 150, 193

Bornstein, S.R. 122, 188

Borrell, J. 182

Bottasso, O. 193

Bozza, V. 193

Calafat, M. 175

Campbell, I.L. 139

Campello-Costa, P. 144

Cano, P. 200

Carrión, M. 134

Cecon, E. 126

Correa, F. 182

De la Fuente, M. 121, 157, 163, 206

De Laurentiis, A. 188

de Meis, J. 213 del Rey, A. 150, 193

Diaz, L.E. 200

Docagne, F. 182

Ehrhart-Bornstein, M. 188

Elverdin, J.C. 188

Esquifino, A.I. 200

Fernandes, P.A.C.M. 126

Fernandez-Solari, J. 188

Ferreira, Z.S. 126

Frank, A. 163

García, J.J. 206

Giraldo, E. 206

Giralt, M. 139

Gomariz, R.P. 134

Guaza, C. 182

Hernangómez, M. 182

Hernanz, A. 157, 163

Hidalgo, J. 139

Hinchado, M.D. 206

Hoffman, M. 150

Jimenez-Ortega, V. 200

Juarranz, Y. 134
Jurgilas, P.B. 144

Kou, W. 150

Larocca, L. 175

Leceta, J. 134

Loría, F. 182

Mahuad, C. 193

Marcos, A. 200

Markus, R.P. 126

Martín, L. 206

Martinez, C. 134

Martins, V.R. 213

McCann, S.M. 188

Mestre, L. 182

Miquel, J. 157

Mohn, C. 188

Molinero, A. 139

Navarro, M. 163

Niemi, M.-B. 150

Nomizo, R. 213

Nova, E. 200

Oliveira-Silva, P. 144

Ortega, E. 206
Pacheco-López, G. 150

Penkowa, M. 139

Perales, J. 144

Pérez Leirós, C. 175

Pezzotto, S.M. 193

Prestifilippo, J.P. 188

Quintana, A. 139

Rettori, V. 188

Roca, V. 175

Romeo, J. 200

Saud, K. 168

Savino, W. 121, 144, 213

Schedlowski, M. 150

Serfaty, C.A. 144

Silva-Barbosa, S.D. 213

Terra-Granado, E. 213

Tichauer, J. 168

Trindade, P. 144

Viveros, M.-P. 157

von Bernhardi, R. 168

\title{
Subject Index Vol. 14, No. 3-4, 2007
}

Adenohypophysis 200

Adrenaline 206

Aging 157

Alcohol, fermented and distilled 200

Alzheimer's disease 163

AM251 188

$\gamma$-Aminobutyric acid 200

Aminothiols 163

Apoptotic acinar cells 175

Associative learning 150

Autoimmunity 134

Behavioral response 157

Cannabinoids 182

CB1 receptor 188

Cell migration 213

Cellular prion protein 213

Chemotaxis 206

Cognitive impairment 163

Cryoinjury 139

Cytokine(s) 168, 193

ERK 168

Exercise 206
Exocrinopathy 175

GFAP-IL6 mice 139

Glia 168

Hormones 193

Hypothalamus 188

IL-1 receptor antagonist 150

IL-2 126

IL-6 139

IL-12 182

IL-1 $\beta 168$

IFN- $\gamma 168$

Immune function 182

- response, impaired 193

Immune-pineal axis 126

Immunosenescence 157

Inflammation 168

Laminin 213

Lipopolysaccharide 150

Lymphocyte subsets 200

Macrophages 175, 206

Matrix metalloproteinases 144

Median eminence 200
Melatonin 126

Mice 157

Microarrays 139

Microbicide activity 206

Microglia 182

Neuroendocrinology 122

Neuroimmune 175

Neuroinflammation 182

Neutrophils 206

Nitric oxide 168, 175

NOD mice 175

Noradrenaline 206

Oxidative stress 157

Phagocytosis 206

Pineal gland 126

Premature aging model 157

Prolactin 200

Receptor for advanced glycation end products, soluble 163

Releasing hormone 122

Retinotectal projections 144

Samuel McCann 122
STAT 168

Stress 157, 206

Submandibulary gland 188

Superior colliculus 144

Synaptic plasticity 144

T regulatory cells 134

Taurine 200

Th17 134

Theiler's virus 182

Thymic hypoplasia 213

Thymocyte differentiation 213

TNF- $\alpha$ 126, 168

- receptor II 163

Topographic map 144

Transcriptome 139

Tuberculosis 193

Vasoactive intestinal peptide 134

Visual system 144

Weight loss 193 